\title{
A Note on the Dyeing of Wool Fabrics Using Natural Dyes Extracted from Rotten Wood-Inhabiting Fungi
}

\author{
Vicente A. Hernández ${ }^{1, *}$, Felipe A. Galleguillos ${ }^{1}$, Nicole Sagredo ${ }^{1}$ and Ángela Machuca ${ }^{2}$ \\ 1 Biotechnology Center, Universidad de Concepción, Concepción 4030000, Chile; \\ felipe.fel1ga21@gmail.com (F.A.G.); nsagredonh@gmail.com (N.S.) \\ 2 School of Science and Technology, Universidad de Concepción, Campus Los Ángeles, Los Ángeles 4440000, \\ Chile; angmachu@udec.cl \\ * Correspondence: vhernandezc@udec.cl; Tel.: +56-41-266-1449
}

Received: 14 December 2017; Accepted: 14 February 2018; Published: 19 February 2018

\begin{abstract}
Fungal isolates obtained from rotten wood samples were identified and selected by their ability to produce fungal dyes in liquid media. Fungal isolates produced natural extracellular dyes with colors ranging from red to orange, yellow and purple. Dyes from two of these fungi, Talaromyces australis (red) and Penicillium murcianum (yellow), were extracted and used to dye wool samples in a Data Color Ahiba IR Pro-Trade (model Top Speed II) machine. The protein nature of wool interacted well with the fungal dyes producing colors suitable for textile applications when used to a concentration of $0.1 \mathrm{~g} \cdot \mathrm{L}^{-1}$. Results on color fastness when washing confirmed the affinity of the dyes with wool as the dyed samples kept their color in acceptable ranges after washing, without the implementation of mordanting pretreatments or the use of fixing agents.
\end{abstract}

Keywords: fungal dyes; Talaromyces; Penicillium; Trichoderma; Fusarium; wool; color fastness

\section{Introduction}

The global demand for natural pigments and dyes have increased over the last years, driven by a major awareness of costumers regarding the harmful effect of several synthetic dyes on human health and the environment [1-4]. The demand for natural pigments and dyes is expected to reach 10 million tons in 2017 [5]. Natural pigments and dyes have been isolated since ancient times from different sources, such as plants, bacteria and fungi [6-10]. Nowadays natural pigments and dyes may be a real alternative to their artificial counterparts in a diverse range of applications at food, cosmetic, pharmaceutical and textile industries [5,11].

In the dyeing of textile products, a number of environmental problems associated with the discharge of artificial dyes to the environment have been reported. Many of these compounds are known for their mutagenic, carcinogenic, allergic and cytotoxic effects [12]. In such sense, the use of natural dyes appears as an alternative to reduce the environmental impact of this industry. Some studies show significant advances in the use of natural pigments and dyes from fungi to color fabrics [2,13-15]. For example, fungal pigments from Chlorociboria aeruginosa (Oeder) Seaver and Scytalidium cuboideum (Sacc. and Ellis) Sigler and Kang and Scytalidium ganodermophthorum Kang, Sigler, Lee and Yun have been used for the staining of polyester, polyamide, cotton and wool [15]. Similarly, color fastness of natural and synthetic fabrics was recently studied with green pigments of C. aeruginosa, red pigments of S. cuboideum and yellow pigments of S. ganodermophthorum [16]. Concerns related to the presence of toxic metabolites in pigments and dyes produced by fungi are commonly raised when evaluating their use for manufactured products. In this regard, the adequate identification of fungal strains and the implementation of toxicity tests is key to ensure a safe environment for workers and harmless products for end users. 
In this note, the potential of filamentous fungi isolated from rotten wood to produce natural dyes usable for wool fabric dyeing was studied. Fungi were isolated, identified and tested on their ability to produce extracellular dyes, i.e., water-soluble compounds with affinity for a textile support, in liquid media. Thereafter, dyes (red and yellow) obtained from two selected fungi were used to dye wool fabrics in a Data Color Ahiba IR Pro-Trade (model Top Speed II) machine. Color fastness when washing was evaluated on the dyed samples.

\section{Materials and Methods}

\subsection{Isolation and Identification of Fungi}

Fungi, collected from decaying Nothofagus spp. logs located in the central and south of Chile (Lircay, Maule region, $35.6097^{\circ} \mathrm{S}, 70.9663^{\circ} \mathrm{W}$; Nonguén, Bio-Bio region, $36.8980^{\circ} \mathrm{S}, 72.9815^{\circ} \mathrm{W}$; Oncol, Los Ríos region, $39.7001^{\circ} \mathrm{S}, 73.3261^{\circ} \mathrm{W}$; and Chiloe, Los Lagos region, $42.6459^{\circ} \mathrm{S}, 73.9354^{\circ} \mathrm{W}$ ), were isolated in Petri dishes with solid media (20 g. $\mathrm{L}^{-1}$ malt extract-agar, $200 \mathrm{mg}$ streptomycin). The isolates were identified by molecular techniques according to the method described by Doyle and Doyle [17]. In brief, DNA extraction from fungal mycelia was performed by using phenol-chloroform and precipitation with isopropanol. The amplification of corresponding internal transcribed spacer (ITS) included the use of universal primers ITS1F and ITS4 [18] and the following temperature cycles: $94{ }^{\circ} \mathrm{C}$ for $4 \mathrm{~min}, 30$ cycles of $94{ }^{\circ} \mathrm{C} 40 \mathrm{~s}, 60{ }^{\circ} \mathrm{C} 40 \mathrm{~s}, 72{ }^{\circ} \mathrm{C}$ for $1 \mathrm{~min}$, and a final elongation step of $72{ }^{\circ} \mathrm{C}$ for $10 \mathrm{~min}$. Resulting PCR products were sequenced in Macrogen facilities in Seoul, Korea. Identity and coverage of sequences was evaluated in the GenBank database using the BLAST algorithm available on the website, https:/ /blast.ncbi.nlm.nih.gov/Blast.cgi [19].

\subsection{Dyes Production}

The fungal isolates were cultured in liquid media containing $20 \mathrm{~g} \cdot \mathrm{L}^{-1}$ malt extract, $200 \mathrm{mg} \cdot \mathrm{L}^{-1}$ streptomycin and distilled water, $\mathrm{pH}$ 5.6. A set of 15 glass flasks $(1 \mathrm{~L})$ containing $500 \mathrm{~mL}$ of liquid media were autoclaved to $121{ }^{\circ} \mathrm{C}$ for $21 \mathrm{~min}$ and then individually inoculated with five agar plugs $(5 \mathrm{~mm})$ of each fungus $(n=3)$. Flasks were then incubated to $130 \mathrm{rpm}$ at $30^{\circ} \mathrm{C}$, for 12 days. Afterward, the liquid media of each flask was collected and filtered using Whatman paper $\mathrm{N}^{\circ} 4$ (Whatman plc, Maidstone, UK) and stored to $4{ }^{\circ} \mathrm{C}$. Colored liquid media obtained after cultivation were extracted with ethyl acetate 1:3 in a $2 \mathrm{~L}$ separation funnel. After the extraction the organic phase was concentrated in a rotevaporator at $50{ }^{\circ} \mathrm{C} ; 120 \mathrm{rpm}$, until drying. The production of each dye was quantified by weight differences.

\subsection{Fabric Dyeing}

Dry dyes (yellow and red) obtained from two selected fungi were used to dye wool samples. Wool was selected because of its affinity with anionic dyes [20], such as those isolated from other dye producing fungi [21]. Crossville Fabric Chile S.A. (Tomé, Chile), a textile company interested in the incorporation of natural dyes in the manufacture of its textile products, donated $100 \%$ wool samples $\left(5 \times 10 \mathrm{~cm}^{2} ; 5 \mathrm{~g}\right)$ with a twill structure, $275 \mathrm{~g} / \mathrm{m}^{2}$, which were dyed in a Data Color Ahiba IR Pro-Trade (model Top Speed II, Datacolor, NJ, USA) machine. The two dried fungal extracts were re-solubilized in distilled water to $0.1 \mathrm{~g} / \mathrm{L}$ and placed in separate containers at the dyeing machine with their respective wool samples $(n=3)$. Dyeing was conducted at $98{ }^{\circ} \mathrm{C}$ for 30 min without the incorporation of a mordanting pretreatment. After dyeing wool samples were dried at room temperature overnight and their color was measured in a spectrophotometer CM-5, Konica Minolta, Tokyo, Japan. Color readings were expressed in the CIE Lab* coordinates. Thereafter, samples were subjected to wet washing according to the protocol established by the quality control department of Crossville Fabric Chile S.A. The protocol, inspired on the AATCC 61/2013 standard [22] is used by the company as a quick test on dyed samples, and involves one cycle of immersion and stirring (60 rpm) for $15 \mathrm{~min}, 60^{\circ} \mathrm{C}$, in distilled water with the anionic detergent Verolan NBO $\left(1 \mathrm{~g} \cdot \mathrm{L}^{-1}\right)$. The samples 
were then dried at room temperature overnight. Color of washed samples was determined again with the spectrophotometer and used to calculate the color difference after washing $(\Delta E)$. $\Delta E$ was reported as color fastness when washing.

\section{Results}

\subsection{Isolation and Identification of Fungi}

Five ascomycete fungi able to produce dyes were isolated and identified by molecular techniques. Fungi included species of Penicillium, Trichoderma, Talaromyces and Fusarium. Identity in all cases was $99 \%$ or higher. Results are shown in Table 1.

Table 1. Identification of fungi isolated from rotten wood samples.

\begin{tabular}{ccccc}
\hline Isolate & GenBank Name & Identity \% (blast) & Access Number & Sequence Size (pb) \\
\hline 1 & Penicillium murcianum & 100 & NR138358 & 575 \\
2 & Talaromyces australis & 99 & NR147431 & 509 \\
3 & Trichoderma spirale & 99 & KP009301 & 549 \\
4 & Talaromyces sp. & 100 & LT558966 & 522 \\
5 & Fusarium oxysporum & 100 & KR997535 & 479 \\
\hline
\end{tabular}

\subsection{Production of Fungal Dyes}

Natural dyes produced by the five identified fungal isolates in liquid media are depicted in Table 2. Yield of dyes ranged from 0.1 to $0.28 \mathrm{~g} \cdot \mathrm{L}^{-1}$, and color obtained were red (T. australis), yellow (P. murcianum and T. spirale), orange (Talaromyces sp.) and purple (F. oxysporum). Due to their color and yield of dyes, T. australis and P. murcianum were selected for further testing on the dyeing of wool fabric. In addition, literature indicates that red dyes from T. australis are monascus type metabolites, i.e., mainly a mixture of rubropunctamine and monascorubramine [21,23]. Similarly, reported metabolites for P. murcianum are griseofulvin and penicillic acid [24]. The use of these compounds in food and pharmaceutical products hints on the likely nontoxic nature of the dyes obtained from these fungi.

Table 2. Yield and color of dyes produced in liquid media by fungi isolated from rotten wood samples.

\begin{tabular}{ccc}
\hline Fungi & Dyes Yield $\left(\mathbf{g} \cdot \mathbf{L}^{-\mathbf{1}}\right)$ & Color \\
\hline Talaromyces australis & 0.22 & Red $^{*}$ \\
Penicillium murcianum & 0.28 & Yellow \\
Talaromyces sp. & 0.10 & Orange \\
Trichoderma spirale & 0.24 & Yellow \\
Fusarium oxysporum & 0.25 & Purple \\
\hline
\end{tabular}

* Selected for wool fabrics dyeing.

\subsection{Dye of Wool Samples}

Natural dyes extracted from T. australis and P. murcianum liquid media were re-solubilized in water and used to dye wool samples. The color obtained to $0.1 \mathrm{~g} \cdot \mathrm{L}^{-1}$ of concentration with both dyes appeared appropriate for textile applications. Color difference after washing indicate a good interaction of wool with the fungal dyes. Color measurements and color differences after wet washing are shown in Table 3. Appearance of control, dyed and washed samples is shown in Figure 1. 
Table 3. Color readings and color difference of dyed samples before and after wet washing.

\begin{tabular}{|c|c|c|c|}
\hline \multirow{2}{*}{ Wool Fabric } & \multicolumn{2}{|c|}{ CIE $L^{*} a^{*} b^{*}$ Color } & \multirow{2}{*}{$\Delta E$} \\
\hline & Before Washing & After Washing & \\
\hline Red & $\begin{array}{c}L^{*}=52(0.2), a^{*}=24.5(1.6) \\
b^{*}=17(0.5)\end{array}$ & $\begin{array}{c}L^{*}=52.5(0.7), a^{*}=23.1(0.3) \\
b^{*}=6.2(0.1)\end{array}$ & $2.1(0.9)$ \\
\hline Yellow & $\begin{array}{c}L^{*}=54.4(1.0), a^{*}=6.3(0) \\
b^{*}=28.5(0.2)\end{array}$ & $\begin{array}{c}L^{*}=54.4(0.7), a^{*}=6.4(0.2) \\
b^{*}=25.6(0.7)\end{array}$ & $2.9(0.5)$ \\
\hline
\end{tabular}
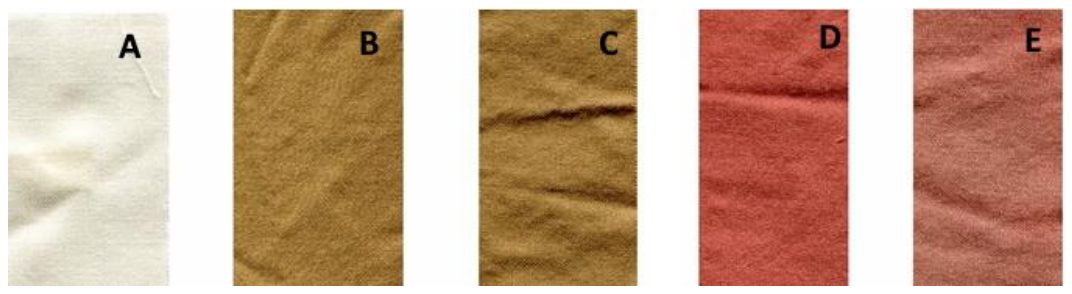

Figure 1. Wool samples dyed with dyes from P. murcianum and T. australis, before and after washing: (A) Control; (B) Sample dyed with P. murcianum dyes; (C) Sample dyed with P. murcianum dyes after washing; (D) Sample dyed with T. australis dyes; (E) Sample dyed with T. australis dyes after washing.

\section{Discussion}

Five fungal isolates were obtained from rotten wood samples and after cultivation in liquid media produced different natural dyes. The isolates corresponded to filamentous fungi Talaromyces australis, Penicillium murcianum, Talaromyces sp., Trichoderma spirale and Fusarium oxysporum. All these fungi were found promoting colorization of wood fiber in rotten wood samples under the bark of sampled logs. The range of dyes obtained varied from yellow, to red, orange and purple. The specific colors are related to the presence of different metabolites secreted by the fungi, which can have a protective role against other microorganisms or to environmental factors [25,26]. All fungal metabolites were shown to be water soluble, which differs from other fungal colored metabolites used experimentally to dye fabrics. For example, those produced by C. aeruginosa, S. cuboideum and S. ganodermophthorum, which are not highly soluble in water [27]. Water solubility increases the possibilities to incorporate fungal metabolites directly into industrial dyeing processes, as water soluble dyeing products are already in use at industrial level.

T. australis and P. murcianum dyes were selected to conduct an exploratory test on wool fabric. The protein nature of wool interacted well with the fungal dyes producing colors suitable for the production of decorative and garment fabrics, when applied to a concentration of $0.1 \mathrm{~g} \cdot \mathrm{L}^{-1}$. Results on color fastness when washing confirmed the affinity of the dyes with wool as the dyed samples kept their color in acceptable ranges after washing, without the incorporation of a mordanting pretreatment or the use of fixing agents. Liquid cultures of pigments and dyes producing fungi, including Talaromyces spp. have been used to dye fabrics directly after the filtration of mycelia and spores [14,28,29]. Color obtained by this method of application highly depends on the yield of the colored metabolites in the media. Since such yield can vary from one batch of culture to another a close control of inoculation and culturing conditions is necessary to achieve an adequate color reproducibility. On the other hand, the extraction and posterior re-solubilization of dyes to specific concentrations seems a less complex method to achieve color reproducibility, which is a requirement to standardize the production of dyed products at industrial level.

In this note the potential of natural dyes obtained from rotten wood inhabiting fungi was demonstrated in term of production, extraction, and applicability on wool fabric. Nevertheless, before the use of these natural dyes can reach industrial application further investigations are necessary in a number of topics. Thus, it is necessary to discard the presence of toxic metabolites by means of toxicity 
tests and also by determining the chemical structure of the dyes. Similarly, it is necessary to study the potential of the other three fungal dyes obtained in this research and to increase the range of colors by continue searching for new fungal isolates. In addition, it is important to study methods to increase the yield of dyes in liquid media in order to decrease the cost of production, test the applicability onto other fabrics, complete a range of color fastness tests, and verify if dyeing conditions used at industrial level may affect the use of these natural dyes. Despite the amount of research that it is still necessary to carry out, the prospect of using natural dyes from fungal isolates on the dyeing of fabrics appears by all means plausible.

Acknowledgments: This work was funded by the Fund for the Promotion of Scientific and Technological Development (FONDEF), Conicyt-Chile, through the Project ID15I10105: "Pigmentos naturales de alto desempeño: una alternativa ecológica en la manufactura de telas de alta calidad", the Biotechnology Center of University of Concepcion and Crossville Fabric Chile S.A.

Author Contributions: Vicente A. Hernández and Felipe A. Galleguillos conceived and designed the experiments; Felipe A. Galleguillos and Nicole Sagredo performed the experiments; Vicente A. Hernández and Ángela Machuca analyzed the data; Vicente A. Hernández and Ángela Machuca contributed reagents/materials/analysis tools; Vicente A. Hernández and Ángela Machuca wrote the paper.

Conflicts of Interest: The authors declare no conflict of interest. The founding sponsors had no role in the design of the study; in the collection, analyses, or interpretation of data; in the writing of the manuscript, and in the decision to publish the results.

\section{References}

1. Venil, C.; Wahidin, M.; Ahmad, W. Production of bacterial pigments in low cost medium and formulation of biodegradable ink. Indian J. Exp. Biol. 2017, 55, 441-447.

2. Panesar, R.; Kaur, S.; Panesar, P. Production of microbial pigments utilizing agro-industrial waste: A review. Curr. Opin. Food Sci. 2015, 1, 70-76. [CrossRef]

3. Srivastava, S. Food adulteration affecting the nutrition and health of human beings. Biol. Sci. Med. 2015, 1, 65-70.

4. Manikprabhu, D.; Lingappa, K. $\gamma$ Actinorhodin a natural and attorney source for synthetic dye to detect acid production of fungi. Saudi J. Biol. Sci. 2013, 20, 163-168. [CrossRef] [PubMed]

5. Rao, M.P.N.; Xiao, M.; Li, W.-J. Fungal and Bacterial Pigments: Secondary Metabolites with Wide Applications. Front. Microbiol. 2017, 8, 1113.

6. Chan-Bacab, M.J.; Sanmartín, P.; Camacho-Chab, J.C.; Palomo-Ascanio, K.B.; Huitz-Quimé, H.E.; Ortega-Morales, B.O. Characterization and dyeing potential of colorant-bearing plants of the Mayan area in Yucatan Peninsula, Mexico. J. Clean. Prod. 2015, 91, 191-200. [CrossRef]

7. Goktas, O.; Duru, M.E.; Yeniocak, M.; Ozen, E. Determination of the color stability of an environmentally friendly wood stain derived from laurel (Laurus nobilis L.) leaf extracts under UV exposure. For. Prod. J. 2008, $58,77-80$.

8. Neeraj, N.; Neera, M.; Sayan, C. Microbial pigments with health benefits-A mini review. Trends Biosci. 2011, $4,157-160$.

9. Hamano, P.; Kilikian, B. Production of red pigments by Monascus ruber in culture media containing corn steep liquor. Braz. J. Chem. Eng. 2006, 23, 443-449. [CrossRef]

10. Robinson, S.; Hinsch, E.; Weber, G.; Freitas, S. Method of extraction and resolubilisation of pigments from Chlorociboria aeruginosa and Scytalidium cuboideum, two prolific spalting fungi. Color. Technol. 2014, 130, 221-225. [CrossRef]

11. Venil, C.; Zakaria, Z.; Ahmad, W. Bacterial pigments and their applications. Process Biochem. 2013, 48, 1065-1079. [CrossRef]

12. Khandare, R.; Govindwar, S. Phytoremediation of textile dyes and effluents: Current scenario and future prospects. Biotechnol. Adv. 2015, 33, 1697-1714. [CrossRef] [PubMed]

13. Velmurugan, P.; Kim, M.-J.; Park, J.-S.; Karthikeyan, K.; Lakshmanaperumalsamy, P.; Lee, K.-J.; Park, Y.-J.; Oh, B.-T. Dyeing of cotton yarn with five water soluble fungal pigments obtained from five fungi. Fibers Polym. 2010, 11, 598-605. [CrossRef] 
14. Chadni, Z.; Rahaman, M.; Jerin, I.; Hoque, K.; Reza, M. Extraction and optimization of red pigment production as secondary metabolites from Talaromyces verruculosus and its potential use in textile industries. Mycology 2017, 8, 48-57. [CrossRef]

15. Weber, G.; Chen, H.; Hinsch, E.; Freitas, S.; Robinson, S. Pigments extracted from the wood-staining fungi Chlorociboria aeruginosa, Scytalidium cuboideum, and S. ganodermophthorum show potential for use as textile dyes. Color. Technol. 2014, 130, 445-452. [CrossRef]

16. Hinsch, E.; Robinson, S. Mechanical color reading of wood-staining fungal pigment textile dyes: An alternative method for determining colorfastness. Coatings 2016, 6, 25. [CrossRef]

17. Doyle, J.; Doyle, L. Isolation of plant DNA from fresh tissue. Focus 1990, 12, 13-15.

18. White, T.; Bruns, T.; Lee, S.; Taylor, J. Amplification and direct sequencing of fungal ribosomal RNA genes for phylogenetics. In PCR Protocols: A Guide To Methods and Applications; Innis, M.A., Ed.; Academic Press: San Diego, CA, USA, 1990; pp. 315-322.

19. Altschul, S.; Madden, T.L.; Schäffer, A.A.; Zhang, J.; Zhang, Z.; Miller, W.; Lipman, D.J. Gapped BLAST and PSI-BLAST: A new generation of protein database search programs. Nucleic Acids Res. 1997, 25, 3389-3402. [CrossRef] [PubMed]

20. IARC Monographs on the Evaluation of Carcinogenic Risks to Humans. Volume 99 Some Aromatic Amines, Organic Dyes, and Related Exposures; World Health Organization, International Agency for Research on Cancer: Lyon, France, 2010.

21. Feng, Y.; Shao, Y.; Chen, F. Monascus pigments. Appl. Microbiol. Biotechnol. 2012, 96, 1421-1440. [CrossRef] [PubMed]

22. AATCC TM61-2013 Colorfastness to Laundering, Home \& Commercial: Accelerated; American Association of Textile Chemists and Colorists: Research Triangle Park, NC, USA, 2013.

23. Visagie, C.; Frisvad, J.; Houbraken, J.; Seifert, K.; Samson, R.; Jacob, K. Five new Talaromyces species with ampulliform-like phialides and globose rough walled conidia resembling T. verruculosus. Mycoscience 2015, 56, 486-502. [CrossRef]

24. Frisvad, J.; Samson, R.; Stolk, A. Disposition of recently described species of Penicillium. Persoonia 1990, 14, 209-232.

25. Langfelder, K.; Streibel, M.; Jahn, B.; Haase, G.; Brakhage, A. Biosynthesis of fungal melanins and their importance for human pathogenic fungi. Fungal Genet. Biol. 2003, 38, 143-158. [CrossRef]

26. Eisenman, H.; Casadevall, A. Synthesis and assembly of fungal melanin. Appl. Microbiol. Biotechnol. 2012, 93, 931-940. [CrossRef] [PubMed]

27. Hinsch, E.; Weber, G.; Chen, H.; Robinson, S. Colorfastness of Extracted Wood-staining Fungal Pigments on Fabrics: A new potential for textile dyes. J. Text. Appar. Technol. Manag. 2015, 9, 1-11.

28. Morales-Oyervides, L.; Oliverira, J.; Sousa-Gallagher, M.; Mendez-Zavala, A.; Montañez, J. Assessment of the Dyeing Properties of the Pigments Produced by Talaromyces spp. J. Fungi 2017, 3, 38. [CrossRef] [PubMed]

29. Sharma, D.; Gupta, C.; Aggarwal, S.; Naqpal, N. Pigment extraction from fungus for textile dyeing. Indian J. Fibre Text. Res. 2012, 37, 68-73.

(C) 2018 by the authors. Licensee MDPI, Basel, Switzerland. This article is an open access article distributed under the terms and conditions of the Creative Commons Attribution (CC BY) license (http://creativecommons.org/licenses/by/4.0/). 